\title{
$A$ CARTA SOBRE A TOLERÂNCIA DE JOHN LOCKE: CONSIDERAÇÕES SOBRE A LAICIDADE*
}

\author{
Flavio Fontenelle Loque** \\ https://orcid.org/0000-0002-6921-8695 \\ flavioloque@yahoo.com
}

RESUMO O propósito do presente artigo é apresentar a defesa da tolerância realizada por John Locke na Carta sobre a Tolerância e avaliar se ela pode ser interpretada como uma reivindicação da laicidade do Estado. De modo mais especifico, o que se almeja é analisar a distinção entre os fins do Estado e da Igreja tal como proposta por Locke e verificar em que medida ela corresponde ao conceito de laicidade formulado na Declaração Universal da Laicidade no Século XXI.

Palavras-chave Estado, Igreja, tolerância, laicidade.

ABSTRACT This article presents John Locke's defence of toleration in the Epistola de Tolerantia and assesses the possibility of interpreting it as a vindication of a secular State. In particular, the goal is to analyse Locke's distinction of the ends of Church and State and to determine to which degree it answers to the concept of laïcite formulated in the Universal Declaration of Laïcité in the $21^{\text {st }}$ century.

Keywords State, Church, toleration, laïcité. 
A reflexão sobre a tolerância na Modernidade está profundamente marcada pela noção de liberdade de consciência ou de direito da consciência errante. ${ }^{1}$ É nesses termos, por exemplo, que Pierre Bayle (1647-1706) desenvolveu o Comentário Filosófico (1686-1688). Acontece, entretanto, que a tolerância na Modernidade também foi pensada a partir de outro conceito fundamental: a finalidade do Estado. Esse é o caso da Carta sobre a Tolerância (1689) de John Locke (1632-1704). De maneira geral, a diferença entre essas duas abordagens implica, por um lado, uma ênfase na ética e na teologia e, por outro, uma ênfase na política. No presente artigo, que se concentra na Carta sobre a Tolerância, é essa segunda abordagem que se pretende explorar. O propósito aqui é apresentar a defesa da tolerância realizada por Locke e avaliar se ela pode ser interpretada como uma reivindicação da laicidade do Estado. De modo mais específico, o que se almeja é analisar a distinção entre os fins do Estado e da Igreja tal como proposta por Locke e verificar em que medida ela corresponde ao conceito de laicidade formulado na Declaração Universal da Laicidade no Século XXI (2005). ${ }^{2}$

Para tanto, convém logo de início determinar o que se entende por tolerância. Locke a define de maneira simples: a tolerância é a abstenção do uso da força (cf. Locke, 1690, p. 2). A simplicidade dessa definição, contudo, exige duas observações suplementares para lhe conferir o devido sentido. A primeira delas consiste em ressaltar que a tolerância que está em jogo no debate da Modernidade é de natureza religiosa, o que significa que o ato de tolerar a que Locke se refere é uma abstenção do uso da força quando se tem como objetivo a imposição de crenças e cultos. A segunda observação relevante para elucidar a definição de tolerância diz respeito ao agente que se valeria da força para impor crenças e cultos. Aos olhos de Locke, a tolerância é um dever que recai sobre os indivíduos, as igrejas, os clérigos e o Estado (cf. Carta, pp. 48-67). ${ }^{3}$ Ao longo da Carta sobre a Tolerância, no entanto, o tratamento dado a cada um desses agentes é desigual, uma vez que Locke se dedica majoritariamente a pensar o Estado. Em última instância, o que de fato lhe interessa é discutir se compete ao poder civil a imposição de crenças e cultos. Fundamentalmente,

1 Sobre a tolerância na Modernidade, cf. Lecler (1994) e Zagorin (2003). Essencialmente, a noção de liberdade de consciência ou de direito da consciência errante refere-se ao direito (e também ao dever) de cada indivíduo formar seu próprio juízo e agir em conformidade com ele.

2 Publicada em vários países, a Declaração Universal da Laicidade no Século XXI foi originalmente apresentada ao Senado francês no centenário da Lei de 9 de dezembro de 1905 referente à separação entre Estado e Igreja na França. Formulada por J. Baubérot, M. Milot e R. Blancarte, a Declaração foi subscrita por 250 intelectuais de 30 países.

3 As referências à Carta sobre a Tolerância, identificada aqui apenas como Carta, remetem à edição bilíngue publicada pela Autêntica Editora em 2019. 
seu objetivo é mostrar que o cuidado com a salvação das almas não é uma atribuição do Estado (mas da Igreja) e que, portanto, é ilegítimo o uso da força para a imposição de crenças e cultos.

Conceber a tolerância nesses termos representava um questionamento da visão predominante nos séculos XVI e XVII, pois o que então se sustentava era que o Estado deveria assegurar a uniformidade religiosa promulgando leis para punir os chamados heterodoxos por suas heresias ou cismas. No limite, o que se propunha era um Estado Absoluto que, estando irmanado à Igreja Verdadeira, teria como uma de suas tarefas o cuidado com a salvação das almas. Defendia-se, assim, uma imbricação entre Estado e Igreja que fazia da coerção um método pastoral e que implicava, além disso, uma associação da heterodoxia à dissidência política e uma tendência a igualar pecado e crime. É desnecessário dizer que, dessa perspectiva, aos cidadãos não se conferia a liberdade de crença e culto e que discriminações legais por motivos religiosos eram tidas como admissíveis. Idealmente, todos deveriam comungar na Igreja estabelecida e adotar o modo de vida prescrito pela religião.

Quanto à laicidade, é um truísmo afirmar que se trata de um conceito com o qual Locke nunca operou. O termo ele próprio é tardio, data do final do século XIX, ${ }^{4}$ de modo que é preciso defini-lo com precisão para que se possa adotá-lo como medida para interpretar a defesa da tolerância realizada por Locke. Afinal, dado o objetivo de avaliar se a Carta sobre a tolerância pode ser compreendida como uma reivindicação da laicidade do Estado, é imprescindível estabelecer um conceito de laicidade a ser utilizado como parâmetro. Nesse sentido, tomando-se como referência a Declaração Universal da Laicidade no Século XXI, considera-se aqui que o conceito em questão é constituído pelos seguintes princípios: (i) a liberdade de crença e culto (art. $1^{\circ}$ ), (ii) a autonomia das leis civis perante qualquer norma religiosa $\left(\operatorname{art.} 2^{\circ}\right.$ ) e (iii) a não discriminação direta e indireta (art. $3^{\circ}$ ). Assim, entendendo a laicidade "como a harmonização, em diversas conjunturas sócio-históricas e geopolíticas, dos três princípios já indicados" (art. $4^{\circ}$ ), a Declaração não estabelece nenhuma relação de dependência entre eles, mas é possível pensar que (ii) a autonomia das leis civis perante qualquer norma religiosa é um meio para se alcançar tanto (i) a liberdade de crença e culto como (iii) a não discriminação direta e indireta. ${ }^{5}$

4 Mais precisamente, segundo Oro (2008, p. 81), de 1871.

5 A relação de dependência (meio-fim) entre os princípios da laicidade é defendida abertamente por Baubérot (2016), Maclure e Taylor (2010) e Baubérot e Milot (2011). Em suas respectivas obras, no entanto, esses autores consideram que a laicidade é composta, a rigor, por duas finalidades, $(\alpha)$ a liberdade de crença e culto (ou liberdade de consciência) e ( $\beta$ ) a não discriminação direta e indireta (ou igualdade), e por dois meios, ( $\gamma$ ) a autonomia das leis civis perante qualquer norma religiosa (ou neutralidade) e $(\delta)$ a separação entre Estado 
Note-se, ainda, que a Declaração não coloca a chamada separação entre Estado e Igreja como um princípio da laicidade, talvez em razão da polissemia (para não dizer obscuridade) dessa fórmula. No momento oportuno, porém, serão apresentadas aqui duas acepções possíveis para essa expressão.

Como dito há pouco, quando Locke se pergunta pela finalidade do Estado, seu intuito é questionar a atribuição ao poder civil do cuidado com a salvação das almas, o que se traduz no esforço conceitual de distinguir os fins do Estado e da Igreja. Na Carta sobre a Tolerância, essa distinção é posta muito claramente por meio das definições de cada uma dessas sociedades:

O Estado me parece ser uma sociedade de homens constituída unicamente para preservar e promover os seus bens civis. ${ }^{6}$ Chamo de bens civis a vida, a liberdade, a integridade do corpo e ausência de dor, bem como a posse de coisas externas, como terras, dinheiro, bens domésticos e outros. (Carta, p. 39)

A Igreja me parece ser uma sociedade livre de homens que se reúnem espontaneamente, a fim de cultuar publicamente a Deus, do modo como acreditam que será aceito pela divindade, para salvação das almas. (Carta, p. 43)

É preciso notar, todavia, que essas definições incorporam a distinção entre os fins do Estado e da Igreja, mas que elas próprias não são argumentos para fundamentá-la. Locke, aliás, tem plena clareza disso e é por esse motivo que, pouco depois de fornecer sua definição de Estado, ele apresenta três justificativas para "demonstrar" que a jurisdição estatal "diz respeito unicamente" aos bens civis, isto é, que todo direito e supremacia do Estado "se limita e se circunscreve somente" a esses bens e que não pode, nem deve "se estender de nenhum modo à salvação das almas" (Carta, p. 39). Em termos lógicos, é como se Locke primeiro apresentasse sua tese (ou conclusão) para, em seguida, prover as razões (ou premissas). Em linhas gerais, são três as justificativas para se recusar a atribuição ao Estado do cuidado com a salvação das almas.

A primeira delas consiste em argumentar que o cuidado com a salvação das almas não foi confiado ao Estado nem por Deus, nem pelos indivíduos. Assim, se ao Estado não foi confiado o cuidado com a salvação das almas, sua

e Igreja. Como se pode perceber, além da diferença quanto ao número, há uma variação nas enunciações dos princípios da laicidade por Baubérot (2016), Maclure e Taylor (2010), Baubérot e Milot (2011) e pela Declaração Universal da Laicidade no Século XXI, mas essas enunciações parecem expressar o mesmo conteúdo conceitual. Assim, por simplicidade e também por clareza, não se busca aqui especificá-las. Por fim, convém apenas registrar que a definição de laicidade em três princípios ou "valores indissociáveis" ocorre também no Relatório Stasi (2003, pp. 9, 66).

6 Na tradução de W. Popple, responsável pela primeira versão inglesa do original latino da Carta sobre a Tolerância, publicada em 1689 e ainda hoje influente, lê-se que o Estado é uma sociedade de homens constituída “...para a obtenção, preservação e promoção de seus interesses civis” (Locke, 1689, p. 6). 
jurisdição se restringe ao encargo de preservar e promover os bens civis. Para Locke, não se pode dizer que Deus tenha confiado ao Estado o cuidado com a salvação das almas porque em parte alguma (da Bíblia, é o que se supõe) essa autoridade lhe foi dada por Ele. Do mesmo modo, agora no que se refere aos indivíduos, afirma-se que eles não confiaram ao Estado o cuidado com a salvação das almas porque a força é um meio inadequado para converter os espíritos.

A segunda justificativa para provar a restrição da finalidade do Estado aos bens civis é uma retomada do argumento da inadequação da força com o intuito de indicar não apenas que os indivíduos não confiaram ao Estado o cuidado com a salvação das almas, mas que esse encargo não pode lhe ser confiado. Trata-se agora, pois, de explicitar que a força atua apenas sobre a vontade, jamais sobre o entendimento, e que por isso é impossível que alguém mude seu juízo sobre as crenças que professa simplesmente por ser coagido: a verdade ou falsidade de uma proposição, tal como ela aparece à mente, não se altera se um indivíduo é multado, preso ou torturado, para citar três exemplos comuns de coerção. A força pode produzir hipócritas, disso não resta dúvida, mas ela é completamente inapta para modificar a "convicção de consciência" (Carta, p. 35). Assim, se a salvação requer justamente essa convicção, conclui-se que a força é inútil e, por conseguinte, que o cuidado com as almas não pode ser um dos fins do Estado.

A terceira justificativa apresentada para mostrar que a finalidade do Estado se restringe à preservação e promoção dos bens civis é uma redução ao absurdo. Raciocinando por concessão, Locke agora supõe que a força pode sim atuar sobre o entendimento e que competiria então ao Estado o cuidado com a salvação das almas. Locke pretende provar que, caso o Estado pudesse impor crenças e cultos, isso seria contraproducente para a salvação das almas. A explicação é simples: supondo que há apenas uma religião verdadeira, a admissão de que o Estado cuide da salvação das almas resultaria na imposição de uma miríade de falsas religiões ao redor do mundo. No cômputo geral, portanto, apenas um pequeno número de pessoas seria salvo. Segundo Locke, nada poderia ser mais indigno de Deus, que assim teria atrelado a salvação ao local de nascimento. Logo, o cuidado com a salvação das almas não pode ser uma finalidade do Estado.

Essas três justificativas apresentadas no início da Carta sobre a Tolerância para provar que a finalidade do Estado é exclusivamente a preservação e promoção dos bens civis parecem se articular da seguinte maneira: o cuidado com a salvação das almas não foi confiado ao Estado, não lhe pode ser confiado 
e, se o fosse, isso traria péssimas consequências. ${ }^{7}$ Noutras passagens da Carta sobre a Tolerância e, em especial, nas cartas escritas ao longo da controvérsia com Jonas Proast (c.1642-1710), seu mais importante crítico nesse debate, Locke haveria de formular novos argumentos para rejeitar a atribuição ao Estado do cuidado com a salvação das almas. Não é o caso de discuti-los aqui, entretanto, pois os três argumentos já apresentados deixam suficientemente claro como a defesa da tolerância realizada por Locke se constitui numa argumentação em prol da delimitação da finalidade do Estado. ${ }^{8}$

Sendo assim, se não cabe ao Estado a responsabilidade pela salvação das almas, convém então perguntar a quem ela caberia. Ora, a quem mais poderia ser senão aos próprios indivíduos e às igrejas às quais eles se vinculam? Como se lê em diferentes passagens da Carta sobre a Tolerância, cada um deve ser deixado a si e à própria consciência. ${ }^{9}$ Todavia, ao tratar do cuidado que cada um deve ter com a própria salvação, Locke introduz uma observação extremamente relevante para ratificar sua posição: o caminho que cada um percorre em busca da vida eterna, por mais equivocado que seja, em nada afeta o próximo. A suposta errância de um indivíduo é inócua para os outros, não lhes causa "dano" (damnum, cf. Carta, p. 87), "prejuízo" (detrimentum, cf. Carta, p. 85) ou "injúria" (injuria, cf. Carta, p. 89), como afirma Locke por meio de um conjunto de noções confluentes. Dessa perspectiva, o que se tem é uma evidente recusa de que a errância possa ser concebida como uma doença contagiosa, à moda do que, poucos anos antes, escrevera Edward Stillingfleet (1635-1699), outro autor com quem Locke haveria de debater publicamente nos anos finais de sua vida. ${ }^{10}$

Se um indivíduo não afeta os bens alheios, os quais incluem as posses, mas também a vida e a liberdade, se não coloca em risco a paz da sociedade civil, é injustificável que ele seja tolhido em seu caminho para a salvação. A esse respeito, tome-se o exemplo da idolatria, tida como pecado, ou da crença católica na transubstanciação, tachada de falsa e absurda. Em ambos os casos,

7 Lennon (1997, pp. 189-190) também pensa haver uma articulação entre as três justificativas, mas ele a formula do seguinte modo: "o controle do magistrado sobre a crença religiosa seria inapropriado, de todo modo impossível e, ainda que possível, improvável para alcançar o efeito intencionado”.

8 Para uma análise mais detalhada tanto dos argumentos de Locke a favor da tolerância quanto da controvérsia com Proast, cf. Silva (2013) e, em especial, Nicholson (1991), Vernon (1997), Jolley (2016), Tate (2016) e Loque (2019).

9 O verbo latino é relinquere, literalmente, deixar, abandonar (cf. Carta, pp. 67, 77, 87).

10 Em O Dano da Separação, Stillingfleet afirma que a dissidência é uma "doença fácil de pegar" (Stillingfleet, 1680, p. 58). Thomas Long (1621-1707), primeiro autor a publicar uma crítica à Carta sobre a Tolerância, haveria de ser ainda mais explícito na associação entre errância e doença contagiosa: "eu acredito que é dever dos magistrados evitar que os homens infectem as almas dos seus súditos com erros destrutivos; se ele pode, legitimamente, confinar um homem que tem a praga no corpo, por que não aquele que tem a praga da heresia na alma?" (Long, 1689, p. 9). 
que pertencem a diferentes caminhos para a salvação, pode-se muito bem tentar persuadir os idólatras e os católicos, mas em hipótese alguma é lícito que as crenças e cultos desses indivíduos sejam objeto de sanção legal. Referindo-se à transubstanciação e a algumas crenças de judeus e muçulmanos, Locke é claro: "as leis não cuidam da veracidade das crenças, mas da proteção e segurança do Estado e dos bens de cada um" (cf. Carta, p. 83). Sendo a finalidade do Estado a preservação e promoção dos bens civis, o critério para a instituição de leis não é e não pode ser religioso. Enunciado por Locke de diferentes maneiras, o critério legislativo é a "utilidade pública" (cf. Carta, p. 69), o "bem comum" (cf. Carta, pp. 75, 87), a "utilidade civil" (cf. Carta, p. 75), o "bem público" (cf. Carta, pp. 87, 89). ${ }^{11}$

$\mathrm{Na}$ Carta sobre a Tolerância, uma das expressões mais claras de que o critério legislativo deve ser autônomo frente às normas religiosas encontra-se no trecho em que Judaísmo e Cristianismo são comparados. O Estado dos judeus era uma teocracia, afirma Locke, porque antes do nascimento de Cristo era impossível haver uma distinção entre os fins do Estado e da Igreja. O que então se tinha era uma identificação entre leis eclesiásticas e civis ou, a rigor, uma subsunção das leis civis às eclesiásticas. Havia assim um regime no qual o próprio Deus era tido como legislador. Aos olhos de Locke, porém, tudo isso se modificou com a vinda de Cristo, cujo ensinamento, seja por palavras, seja pelo exemplo, é de natureza moral, o que significa que sua pregação, tendo se limitado a anunciar o caminho para a vida eterna, jamais esteve voltada para o Estado, exceto quando foi preciso desatrelar política e fé. Numa passagem lapidar, Locke sintetiza sua posição acerca desse ponto do seguinte modo:

Mas não há absolutamente nenhum Estado cristão sob o Evangelho. [...] Ele [Cristo] ensinou a cada um com que fé e com que costumes deve ser obtida a vida eterna, mas não instituiu nenhum Estado, não introduziu nenhuma forma nova de sociedade civil peculiar ao seu povo, não armou magistrados com uma espada com a qual os homens fossem coagidos à fé e ao culto que propôs aos seus e com a qual fossem afastados das instituições de uma religião estrangeira. (Carta, pp. 79-81)

Sendo assim, a despeito da importância do comentário acerca do regime teocrático, que representa o máximo da indistinção entre os fins do Estado e da Igreja, já que elimina a própria dualidade entre as ordens civil e eclesiástica,

11 Nos Dois Tratados sobre o Governo, Locke apresenta essa mesma posição ao dizer que o poder legislativo "não deve estar dirigido a outro fim senão a paz, a segurança e o bem público do povo" (cf. DTG, II § 131). Nos termos de Bignotto (2004, p. 66), "a tolerância religiosa, que permanece viva até hoje nos países de tradição democrática liberal, implica na verdade a destituição do caráter político da religião e a ordenação formal da vida política segundo princípios que não aceitam a interferência dos credos particulares". 
o grande objetivo da comparação do Judaísmo ao Cristianismo é mostrar que Cristo não buscou instituir um Estado guiado por preceitos religiosos. A ênfase sobre a inexistência de um "Estado cristão" corrobora, portanto, a proposição de que o critério legislativo deve ser a utilidade pública. No que se refere à laicidade, isso significa que a autonomia das leis civis perante qualquer norma religiosa é o meio para se garantir a liberdade de crença e culto e para que não sejam instituídas discriminações (ao menos não discriminações diretas) a fim de se privilegiar uma confissão em detrimento das outras, como ocorria na Inglaterra, por exemplo, com a Lei do Teste (1673), que fazia da comunhão na Igreja Anglicana uma condição para que os indivíduos assumissem cargos públicos. ${ }^{12}$

A esse respeito, no entanto, deve-se observar que o critério legislativo proposto por Locke, embora vete quaisquer discriminações diretas, não elimina a possibilidade de discriminações indiretas. Para Locke, em circunstâncias específicas, algumas religiões podem sofrer indiretamente algum tipo de cerceamento. É isso que se vê num exemplo bastante elucidativo dado por ele próprio. Trata-se do episódio no qual, em decorrência de uma carestia alimentar, proíbe-se o abate de bezerros, mesmo sabendo-se que uma lei como essa interfere nos cultos em que há imolações. Segundo Locke, dada a razão que o justifica, esse interdito é legítimo, pois ele não possui motivação religiosa, mas política: "não é sobre matéria de religião, mas de política que é feita a lei" (Carta, p. 75). A rigor, o objetivo não é cercear qualquer culto, mas garantir a recomposição do estoque de alimentos, o que condiz com a finalidade do Estado de preservar e promover os bens civis, entre os quais se encontra a vida. ${ }^{13}$

12 Na correspondência entre Locke e Philip van Limborch (1633-1712), seu amigo holandês a quem a Carta sobre a Tolerância foi dedicada, há uma crítica a esse tipo de discriminação numa carta de Limborch a Locke datada de 8/18 de julho de 1689. Ocorrida a promulgação da Lei da Tolerância em 24 de maio de 1689, a qual apenas suspendeu as punições de parte da legislação que cerceava o culto público dos dissidentes trinitários (a Lei do Teste, vale lembrar, permaneceu em vigor), Locke comentou em 6 de junho de 1689, sem entrar em detalhes, que a Lei da Tolerância não é "tão ampla em abrangência", mas que "representa um progresso", o que permitiu a Limborch observar que, idealmente, "a melhor regra é que todos sem distinção, desde que sejam todos bons cidadãos, deveriam possuir os direitos de cidadania em igual medida e que a ninguém, contanto que não ofenda as leis do Estado, deveria ser negado aquilo que pertence a todos igualmente pela lei da natureza". Noutras palavras, Limborch parece fazer referência, por um lado, à não discriminação direta, sob a forma de uma defesa da igualdade nos direitos de cidadania, e, por outro, à liberdade de crença e culto, aludindo à lei da natureza (cf. Locke, 1976-1989, v. III, cartas 1147, 1158).

13 Como aponta McCabe (1997, pp. 242-243), o critério legislativo proposto por Locke corresponde ao que se pode chamar de neutralidade de justificativa, não de neutralidade de efeito. Quando hoje se discutem as "acomodações razoáveis", o que se busca é atenuar ou extinguir a discriminação indireta (cf. Bouchard e Taylor, 2008, pp. 24-27). Nesse sentido, Maclure e Taylor (2010, p. 84) observam: "se John Locke, na Carta sobre a Tolerância, admitia de bom grado que a liberdade de consciência incluía a liberdade de manifestar as crenças religiosas, ele não acreditava que ela continha também a obrigação de acomodar os crentes que se debatem com um conflito entre uma lei servindo ao interesse coletivo e uma prescrição religiosa". 
Dessa perspectiva, feita a ressalva acerca da discriminação indireta, é possível então dizer que a defesa da tolerância realizada por Locke pode ser interpretada como uma reivindicação da laicidade do Estado. Ressalte-se, porém, que para tanto é preciso haver uma distinção dos fins do Estado e da Igreja, mas não uma separação entre Estado e Igreja, subentendendo-se por isso que o Estado deva prescindir de uma religião oficial e de sua subvenção. Em termos históricos, esse processo de desconfessionalização do Estado ocorreu, por exemplo, no Brasil e na França, mas não na Inglaterra, onde o Anglicanismo continua a ser a religião oficial. ${ }^{14} \mathrm{Na}$ Carta sobre a Tolerância, não é clara a posição de Locke a esse respeito, ${ }^{15}$ de modo que sua defesa da tolerância não parece requerer o fim da confessionalidade do Estado e da subvenção da religião oficial (ou, quando é o caso, das religiões reconhecidas). ${ }^{16}$

Seja como for, é preciso ainda notar que a distinção entre os fins do Estado e da Igreja não representa para Locke nem a redução do valor da religião na vida dos indivíduos, nem seu enclausuramento na esfera privada. ${ }^{17}$ A defesa da

14 Do ponto de vista legal, os documentos emblemáticos a esse respeito são, no caso do Brasil, o Decreto 119-A de 7 de janeiro de 1890 e, no caso da França, a Lei de 9 de dezembro de 1905. Quanto à Inglaterra, a associação entre a regência política e eclesiástica remonta às leis de supremacia da dinastia Tudor (de 1534, por Henrique VIII, e de 1559, por Elizabeth I). Para um inventário muito interessante acerca da relação entre Estado e Igreja em 197 países a partir de uma tipologia que os divide em Estados religiosos, confessionais, laicos e irreligiosos, cf. Kuru (2007, pp. 247-254).

15 Segundo Goldie, em sua introdução à edição da Carta sobre a Tolerância e Outros Escritos, "não é claro se Locke era um separacionista categórico. [...] Se assumirmos que Locke foi um separacionista categórico, então não é na Inglaterra e na Escócia que se deve procurar um Estado moderno lockiano, mas nos Estados Unidos, onde o argumento de Locke na Carta foi incorporado ao Estatuto da Virgínia para a Liberdade Religiosa (1779) de Thomas Jefferson, ou na França, com sua tradição republicana secular de laïcité" (cf. Locke, 2010, p. xiv). De acordo com Coffey (2000, p. 12), Locke foi um tolerantista radical que defendeu "o direito natural ou o simples direito [natural right or entitlement] dos dissidentes religiosos de cultuar livremente e gozar de igualdade civil", mas que somente "os mais radicais tolerantistas deram um passo a mais e advogaram o que posteriormente foi chamado de disestablishment ou separação entre Estado e Igreja". Tratando desse mesmo problema, McCabe (1997, p. 246) observa que "o argumento de Locke a favor da neutralidade do Estado frente à religião não implica logicamente a doutrina da estrita separação entre Estado e Igreja”. A propósito, convém observar que a expressão "separação entre Estado e Igreja" ou, a rigor, "muro de separação entre Estado e Igreja", que Thomas Jefferson (1743-1826) haveria de popularizar, remonta não a Locke, mas a Roger Williams (1603-1683), como aponta Baubérot (2016, pp. 15-16).

16 A adoção de uma religião oficial e sua subvenção é o que frequentemente define o Estado Confessional. Em alguns casos, porém, nos quais não mais se fala propriamente em Estado Confessional, há a subvenção das religiões reconhecidas pelo Estado, como no regime concordatário francês no século XIX. Para uma discussão da laicidade quando um Estado possui uma religião oficial e a subvenciona, como é o caso hoje da Dinamarca, cf. Laegaard (2011). Para uma reflexão mais ampla sobre os regimes de confessionalidade e de separação nos países da Europa ocidental, cf. Portier (2011).

17 Entende-se aqui a oposição entre esfera pública e privada no segundo dos sentidos apresentados por Bouchard e Taylor (2008, p. 45): "com efeito, a palavra "público" pode ser entendida ao menos de duas maneiras diferentes. No primeiro sentido, é público o que concerne ao Estado e às instituições comuns (fala-se assim em "instituições públicas"). No segundo sentido, é público o que é aberto e acessível a todos (fala-se então de "lugares públicos": por exemplo, de um "jardim aberto ao público"). O primeiro sentido está de acordo com o princípio da laicidade da neutralidade do Estado face às religiões. Conforme o primeiro sentido, é então justo afirmar que a religião deve ser "privada". Todavia, não é evidente que a laicidade exija que a religião esteja ausente do espaço público no sentido amplo". 
tolerância se resume a uma avaliação da finalidade do Estado (o que diz respeito, por assim dizer, ao ordenamento jurídico) ao passo que a redução do valor da religião na vida dos indivíduos e seu enclausuramento na esfera privada são fenômenos relacionados aos costumes e à cosmovisão dos cidadãos, fenômenos que se enquadram no que normalmente é descrito como secularização, não como laicidade. ${ }^{18}$

Na Carta sobre a Tolerância, é bastante claro que Locke jamais deixou de conceber o ser humano como atrelado e dependente dos propósitos divinos: detentor de uma alma imortal, a preocupação com ela e com seu destino deve prevalecer sobre qualquer injunção secular. "Primeiramente, deve-se obediência a Deus, depois, às leis" (Carta, p. 87), como aconselha Locke ao aventar a possibilidade de conflito entre as leis civis e a consciência individual. Nos Dois Tratados sobre o Governo (1689), essa hierarquização fica explícita quando se lê que homens e mulheres são um "artefato de um mesmo Criador" e que foram "enviados ao mundo por Sua ordem e para cumprir Seus desígnios" (cf. DTG, II $\S \S 6-7)$, consubstanciados na lei da natureza. Para Locke, portanto, a defesa da distinção entre os fins do Estado e da Igreja em nada altera a centralidade que a religião possui (e deve possuir, pensa ele) na vida dos indivíduos. ${ }^{19}$

Do mesmo modo, o enclausuramento da religião na esfera privada revelase incompatível com a Carta sobre a Tolerância. Locke não apenas admite a presença de manifestações religiosas na esfera pública, como parece concebê-la como palco de investidas proselitistas. A esse respeito, convém lembrar que Locke reconhece abertamente que o culto a Deus deve ter caráter público, como se vê em sua definição de Igreja, mas também que ele chega a dizer que admoestações caridosas e o empenho para refutar erros são os "maiores deveres dos cristãos" (Carta, p. 85). ${ }^{20}$ Particularmente quanto à dimensão proselitista das religiões, o que de fato lhe importa em sua reflexão sobre a tolerância é o método de conversão a ser empregado. O uso da força é inaceitável, já a persuasão é plenamente admissível: "a qualquer um é lícito usar quantas

18 A ausência de uma apreciação adequada da diferença entre a laicidade e esses dois outros fenômenos é a razão de o conceito de secularização às vezes ser aplicado a Locke, como faz Kateb (2009), que enfatiza em sua interpretação a relação entre religião e moralidade. Para uma introdução aos conceitos de laicidade e secularização, cf. Baubérot (2013), Cunha e Oliva (2014), Lacerda (2014), Cury (2018) e Ranquetat Jr (2008). Nos termos de Baubérot (2016, p. 46), "esquematicamente, a secularização implica a perda da pertinência social dos universos religiosos nas sociedades modernas que funcionam, progressivamente, segundo os critérios de racionalidade instrumental ligados às ciências e às técnicas. [...] A laicização diz respeito à governança política da religião e coloca em jogo suas relações com o Estado nação." Para uma análise crítica do conceito de secularização, cf. Baubérot e Milot (2011, pp. 161-194).

19 Sobre a cosmovisão religiosa de Locke e as interpretações de sua filosofia, cf. Ashcraft (1996) e Sigmund (2005).

20 Sobre o dever de evangelizar e a tolerância, cf. Goldie e Popkin (2006, pp. 99-104). 
exortações e argumentos quiser para a salvação de outrem, mas deve abster-se de toda a força e coerção e nada deve ser feito em prol do domínio" (Carta, p. 85). Dos indivíduos, conclui-se, não se espera que eles ocultem sua religiosidade: os cultos têm de ser públicos, como inevitavelmente também têm de ser os esforços proselitistas, os quais estão autorizados a ocorrer desde que feitos de maneira não coercitiva e, como ressalta Locke, sem buscar o domínio.

Na Carta sobre a Tolerância, todavia, há algumas restrições à religião no espaço público. Isso se dá nos casos que constituem os limites à tolerância. Locke os enumera e descreve com clareza, embora deixe de apresentar as punições que lhes seriam cabíveis. Todos esses casos se enquadram na categoria de crenças práticas, ou seja, na categoria de crenças que, ao contrário das especulativas, influenciam a ação ou o comportamento potencial dos indivíduos. Aos olhos de Locke, são quatro os grupos de crenças práticas intoleráveis.

O primeiro diz respeito às crenças que são incompatíveis ou contrárias à preservação da sociedade. Locke não fornece nenhum exemplo de crenças desse tipo, apenas observa que raramente são sustentadas nas igrejas, pois não é razoável a profissão de algo que solapa os fundamentos sociais e que é universalmente condenado pelos indivíduos.

O segundo grupo abarca as crenças que indicam uma propensão dos que as professam a se colocar contra o direito civil e, portanto, havendo ocasião oportuna, a violar as leis civis e a liberdade e posses dos cidadãos. Evidentemente, como ressalta Locke, ninguém jamais dirá abertamente que são essas suas reais intenções. As crenças intoleráveis desse segundo grupo caracterizam-se, portanto, por serem capciosas, na medida em que precisam mascarar seu real significado. Locke fornece três exemplos: não se deve manter a promessa aos hereges, os reis excomungados podem ser destituídos e o domínio se funda na graça. Em seguida, apontando que os indivíduos que as professam consideram a si mesmos detentores da verdade, Locke então esclarece que aquelas crenças significam, a rigor, que esses indivíduos não precisam manter nenhuma promessa, pois, comparados a si próprios, os outros são sempre heterodoxos; que os reis podem ser destituídos por eles, já que ninguém mais possui direito de excomunhão; e que o domínio de todas as coisas lhes pertence, por serem os únicos pios e fiéis. Em suma, o que está em jogo nesse segundo grupo de crenças intoleráveis é um "privilégio ou poder acima dos demais mortais nos assuntos civis", um "poder contra os homens que não são de sua comunhão eclesiástica" e uma recusa em "ensinar que os outros, os dissidentes de sua religião, devem ser tolerados" (Carta, p. 93).

O terceiro grupo de crenças práticas intoleráveis compreende as crenças que exigem de um indivíduo a obediência ao rei de um país estrangeiro. $\mathrm{O}$ 
Estado não deveria tolerá-las por um motivo simples: em caso de conflito, os indivíduos que as professam podem se voltar contra o rei do país em que vivem. $\mathrm{Na}$ Carta sobre a Tolerância, Locke exemplifica seu raciocínio mencionando os muçulmanos, mas esse tipo de argumento era comumente empregado contra os católicos, como fez o próprio Locke anos antes em seu Ensaio sobre a Tolerância (1667). ${ }^{21}$

O quarto e último grupo de crenças práticas intoleráveis é composto exclusivamente pelo ateísmo, que para Locke não deve ser admitido pelo Estado porque, de sua perspectiva, as promessas, pactos e juramentos perdem todo valor quando um indivíduo não acredita em Deus. Para Locke, noutras palavras, a negação da Divindade retira o embasamento último dessas três formas de vínculo social e, por isso, ameaça a existência da sociedade. ${ }^{22}$

Esses quatro grupos de crenças constituem, como se viu, os limites da tolerância, o que significa que o Estado estaria legitimado em empregar a força em todos esses casos. A liberdade de crença e culto, afinal, é um direito condicionado: os bens alheios e a ordem pública não podem ser afetados. Evidentemente, esse é um uso da força voltado para questões religiosas, mas isso em momento algum configura uma violação da finalidade do Estado porque a força não é usada com motivação religiosa. Só se poderia falar em violação da finalidade do Estado (e, por isso, em injustiça ou perseguição) caso um indivíduo ou igreja fosse punido por suas crenças religiosas enquanto tais. Não é o que se passa aqui. Não se julga a dimensão religiosa da crença (se é verdadeira ou falsa, se agrada ou não a Deus), mas sua dimensão política (a ameaça seja à paz, seja às posses, liberdade e vida dos cidadãos). $\mathrm{O}$ critério para estabelecer o intolerável, portanto, é de natureza exclusivamente política e corresponde à finalidade do Estado de preservar e promover os bens civis. Ocorre nesses quatro casos o que deve ocorrer em quaisquer outros. Dado que os fins do Estado e da Igreja são distintos, é o bem público que orienta a legislação e que torna legítima sua aplicação. Nos termos do próprio Locke, "a utilidade pública é o limite e a medida para a elaboração das leis" (Carta, p. 69).

Sendo assim, estabelecida a distinção entre os fins do Estado e da Igreja e, por conseguinte, o critério a partir do qual as leis devem ser formuladas, resta compreender como pode vir a ocorrer o emprego da coerção por parte do Estado com o objetivo de impor crenças e cultos e de discriminar certos grupos religiosos. Por que acontece de o Estado não respeitar os fins que lhe são próprios? Na Carta sobre a Tolerância, Locke aventa uma hipótese para 
explicar porque isso acontece. Basicamente, trata-se de um conluio entre o rei e os clérigos no qual, além dos ganhos pecuniários para ambas as partes, o rei obtém o endosso de sua autoridade e os clérigos adquirem poder. Em termos concretos, troca-se apoio político, normalmente sob a forma de uma apologia do direito divino dos reis, ${ }^{23}$ por um viés legislativo que leve à perseguição dos supostos heréticos e cismáticos. Com o intuito de corroborar sua própria autoridade, como se a religião fosse um meio legítimo para tanto, o rei permite que, ao menos em parte, as leis sejam elaboradas a partir de preceitos religiosos dos clérigos com quem se alia. Na Carta sobre a Tolerância, Locke é irônico ao denominar esse conluio, "concórdia de Igreja e Estado" (Carta, p. 103), e não se poupa de fazer comentários derrogatórios acerca dos clérigos, destacando ora sua volubilidade, ora sua ambição.

Essa descrição da "concórdia de Igreja e Estado" é muito interessante porque explica a violação da autonomia das leis civis frente às normas religiosas e demonstra que a consequência disso é a perseguição, ou seja, a corrupção dos princípios de liberdade de crença e culto e de não discriminação. A “concórdia de Igreja e Estado" é ainda interessante, porém, na medida em que permite pensar um aspecto eminentemente político da laicidade. Conforme definida anteriormente, a laicidade é composta pelos princípios da liberdade de crença e culto, da não discriminação direta e indireta e da autonomia das leis civis perante qualquer norma religiosa, mas ela pode ainda ser concebida levando-se em conta o problema do fundamento do poder civil. A rigor, trata-se de destacar o quanto aqueles três princípios parecem depender de uma separação entre Estado e Igreja, entendendo-se agora por isso um processo de legitimação do poder civil independente da religião. ${ }^{24}$ A julgar pela Carta sobre a Tolerância, mas igualmente pelos Dois Tratados sobre o Governo, é inegável que Locke advoga essa independência. Sobretudo por sua crítica a Robert Filmer (c. 1588-1653), não resta dúvida de que Locke recusa qualquer fundamento transcendente e de que ele propõe que a legitimidade do Estado deriva do consentimento e da confiança dos cidadãos: o que importa é o contrato (ou pacto) que os indivíduos estabelecem entre si e o encargo que delegam ao Estado. ${ }^{25}$

23 Cf. Locke, 2002, p. 234 (Locke, 2007, p. 290).

24 A Declaração Universal da Laicidade no Século XXI menciona com clareza o processo de legitimação do poder civil independente da religião (cf. art. 5), mas, como apontado anteriormente, não chega a formulá-lo como um princípio. Para uma compreensão da laicidade que enfatiza a questão da legitimidade do poder civil, cf. Blancarte (2008). A importância da separação entre Estado e Igreja para a obtenção da liberdade de consciência e da não discriminação explica o sentido da divisão quadripartite dos princípios da laicidade proposta por Baubérot (2016), Maclure e Taylor (2010) e Baubérot e Milot (2011), conforme apontado em nota anterior.

25 Quando se comparam Locke e Bayle, a crítica ao absolutismo marca uma diferença importante entre eles, pois, como apontam Baubérot e Milot (2011, p. 62), falta a Bayle "um traço estrutural fundamental da laicidade" 
Em sua descrição da "concórdia de Igreja e Estado", entretanto, além de explicitar o problema do fundamento do poder civil, Locke também observa que, com o desvirtuamento do critério legislativo e os efeitos que daí advêm sobre a liberdade de crença e culto e a não discriminação, é inevitável que os indivíduos e igrejas oprimidos reajam e busquem se livrar da injustiça de que são alvo. Se o Estado não assegura direitos iguais para que todos os indivíduos e igrejas professem as crenças e cultos que julgam verdadeiros e agradáveis a Deus, é de se esperar (e é lícito) que haja resistência. Naturalmente, a resistência acabará gerando conflitos, mas é preciso perceber que esses conflitos não decorrem da existência de diferentes religiões, como então frequentemente se dizia. Locke é incisivo: "não é a diversidade de crenças, o que não se pode evitar, mas a tolerância negada aos que têm crenças diferentes, o que poderia ser concedido, que produziu a maior parte das guerras e disputas sobre religião que nasceram no mundo cristão" (Carta, p. 103). ${ }^{26}$ Os conflitos, em suma, não são provocados pela diversidade, mas pela intromissão de uma religião no Estado, o que aniquila a utilidade pública como critério de instituição das leis e acaba por violar tanto a liberdade de crença e culto quanto a não discriminação. A tolerância, assim, revela-se o único caminho para a paz, pois, caso tenham seus direitos assegurados, todos os indivíduos e igrejas outrora perseguidos deixarão de ter motivos para se insurgir contra o Estado e passarão a apoiá-1o. ${ }^{27}$

Portanto, tomando a Carta sobre a Tolerância como um todo, pode-se então concluir que a recusa de que o cuidado com a salvação das almas seja uma finalidade do Estado equivale à adoção da utilidade pública como critério legislativo. Dito noutras palavras, isso significa que a delimitação dos fins do Estado à preservação e promoção dos bens civis consiste numa restrição dos casos nos quais a coerção pode ser considerada legítima, estabelecendo, por contraste, aqueles nos quais é justo resistir. ${ }^{28} \mathrm{~A}$ imposição de crenças e cultos,

por ele não partilhar "de modo algum a ótica lockiana de um magistrado com poder puramente civil". Sobre a defesa da tolerância e a oposição entre o absolutismo de Bayle e o contratualismo de Locke na recepção da tradução francesa do Segundo Tratado sobre o Governo, cf. Savonius (2004, pp. 63-65).

26 A esse respeito, convém destacar que em momento algum da Carta sobre a Tolerância há um elogio da diversidade à moda, por exemplo, do que J. S. Mill (1806-1873) haveria de fazer no Sobre a Liberdade. Locke encara a diversidade de um ponto de vista puramente prático ou factual: o Estado deve constatar sua existência e lidar com ela de modo a assegurar a paz, dado ser irrealista supor que a estabilidade política possa advir da uniformidade.

27 Nesse mesmo sentido, mas em sua correspondência com Limborch, Locke escreve em 10 de setembro de 1689: "os homens sempre diferirão em questões religiosas e partidos rivais continuarão a brigar e fazer guerra uns contra os outros a menos que o estabelecimento da igual liberdade para todos crie um vínculo de caridade mútua pelo qual todos possam se reunir num só corpo" (cf. Locke, 1976-1989, v. III, carta 1182).

28 Como afirma Bobbio (2013), a reflexão moderna sobre o Estado envolve duas formas de limitá-lo: quanto ao exercício do poder e quanto à função (ou finalidade). Em termos históricos mais amplos, a limitação quanto ao exercício do poder culminará na noção de Estado de Direito; a limitação quanto à função, na noção de Estado Mínimo. Dessa perspectiva, não deve haver dúvida de que a defesa da tolerância (ou mutatis mutandis da 
consequentemente, é de todo injustificável, razão pela qual a defesa da distinção dos fins do Estado e da Igreja é ao mesmo tempo uma defesa da tolerância. Quanto aos indivíduos, claro, a distinção dos fins do Estado e da Igreja resulta no aumento do âmbito de sua liberdade, donde a afirmação de Locke segundo a qual, no que se refere à salvação, cada um deve ser deixado a si mesmo e à própria consciência. Evidentemente, todavia, esse aumento do âmbito da liberdade individual não é irrestrito: nenhuma crença ou culto que ameace a paz ou que coloque em risco os bens alheios é tolerável.

Em síntese, a argumentação de Locke em prol da tolerância implica que a regulamentação da vida civil, que abarca a sociedade como um todo, não pode estar orientada pelos princípios de nenhuma religião. Como se buscou mostrar ao longo do presente artigo, essa defesa da tolerância pode ser concebida como uma reivindicação da laicidade do Estado tal como esse conceito é definido nos três princípios presentes na Declaração Universal da Laicidade no Século XXI (feita a ressalva, vale lembrar, acerca da não discriminação indireta). A Carta sobre a Tolerância, no entanto, fornece ainda elementos para pensar a laicidade relacionando-a ao problema do fundamento do poder civil. Como se viu na crítica de Locke à "concórdia de Igreja e Estado", a violação da autonomia das leis civis frente a qualquer norma religiosa e o consequente comprometimento tanto da liberdade de crença e culto como da não discriminação direta e indireta estão associados à tentativa de o Estado legitimar seu poder pela religião por meio da aliança com clérigos inescrupulosos. Nesse sentido, é então perfeitamente adequado dizer que a laicidade também envolve a separação entre Estado e Igreja entendida não como desconfessionalização e não subvenção, mas como um processo de legitimação do poder civil independente da religião. ${ }^{29}$

\section{Referências}

ASHCRAFT, R. "Religion and Lockean Natural Rights". In: BLOOM, I., MARTIN, J. P., PROUDFOOT, W. L. (eds.). Religious Diversity and Human Rights. New York: Columbia University Press, 1996. pp. 195-212.

laicidade) filia-se à discussão sobre a função do Estado. O Estado Laico é, por assim dizer, um caso particular do Estado Mínimo, na medida em que representa o questionamento de uma função específica.

29 Esse artigo foi originalmente apresentado na mesa-redonda "Filosofia, Política, Laicidade e Direitos Humanos" na $71^{\mathrm{a}}$ reunião anual da Sociedade Brasileira para o Progresso da Ciência, ocorrida na Universidade Federal do Mato Grosso do Sul, em julho de 2019. Pelo convite para participar do evento, agradeço aos professores Luiz Antônio Cunha, Cláudia Masini D’Ávila-Levy e, em especial, José Raimundo Maia Neto. Pela leitura e comentários ao presente artigo, agradeço ainda a Hélio Dias e Natália Tavares, mas particularmente ao professor Newton Bignotto. Por fim, meu agradecimento aos pareceristas do artigo, cujas sugestões foram incorporadas ao texto. 
BLANCARTE, R. "O porquê de um Estado Laico". In: LOREA, R. A. (org.). Em defesa das liberdades laicas". Porto Alegre: Livraria do Advogado, 2008. pp. 19-32. BAUBÉROT, J. (2007). "Les Laïcités dans le Monde". 4. ed. Paris: PUF, 2016. "Sécularisation, laïcité, laïcisation". Empan, Nr. 90, 2013, pp. 31-38. BAUBÉROT, J., MILOT, M. "Laïcités sans Frontières". Paris: Seuil, 2011. BAYLE, P. (1686) "De la Tolérance - Commentaire Philosophique". Édité par J.-M. Gros Paris: Honoré Champion, 2014.

(1688) "Supplément du Commentaire Philosophique". Introduction et annotations par M. Pécharman. In: ZARKA, Y. C., LESSAY, F., ROGERS, J. (eds.) Les Fondements Philosophiques de la Tolérance Paris: PUF, 2002. Tome III.

BIGNOTTO, N. "Tolerância e Diferença". In: NOVAES, A. (org.) Civilização e Barbárie. São Paulo: Companhia das Letras, 2004.

BOBBIO, N. (1988). "Liberalismo e Democracia". Trad. M. A. Nogueira São Paulo: Brasiliense, 2013.

BOUCHARD, G., TAYLOR, C. "Fonder L'Avenir: le temps de la conciliation". Gouvernement du Québec, 2008. (Rapport Abrégé)

COFFEY, J. "Persecution and Toleration in Protestant England 1558-1689". Edinburgh: Longman, 2000.

COMMISSION de réflexion sur l'application du principe de laïcité dans la République Rapport au Président de la République Médiateur de la République B. Stasi. Rémis le 11 décembre 2003.

CUNHA, L. A., OLIVA, C. E. "Sete teses equivocadas sobre o Estado Laico". In: BRASIL. Ministério Público em Defesa do Estado Laico. Brasília: Conselho Nacional do Ministério Público, 2014. Vol. I. pp. 207-227.

CURY, C. R. J. "Por uma concepção do Estado Laico". In: D’AVILA-LEVI, C. M., CUNHA, L. A. (orgs.). Embates em torno do Estado Laico. São Paulo: SBPC, 2018. pp. 41-52.

"Declaração universal da laicidade no século XXI" (2005). In: LOREA, R. A. (org.). Em defesa das liberdades laicas. Porto Alegre: Livraria do Advogado, 2008. pp. 7-11. GOLDIE, M., POPKIN. R. "Scepticism, priestcraft, and toleration". In: GOLDIE, M., WOKLER, R. (eds.). The Cambridge History of the Eighteenth-Century Political Thought. Cambridge: Cambridge University Press, 2006. pp. 79-109.

JOLLEY, N. "Toleration \& Understanding in Locke". Oxford: Oxford University Press, 2016.

KATEB, G. "Locke and the Political Origins of Secularism". Social Research, Vol. 79, Nr. 4, 2009, pp. 1001-1034.

KURU, A. T. "Secularism and State Policies toward Religion: The United States, France, and Turkey". Cambridge: Cambridge University Press, 2007.

LACERDA, G. B. "Sobre as relações entre Igreja e Estado: conceituando a laicidade". In: BRASIL. Ministério Público em Defesa do Estado Laico Brasília: Conselho Nacional do Ministério Público, 2014. Vol. I. pp. 179-205. 
LAEGAARD, S. "Religious Neutrality, Toleration and Recognition in Moderate Secular States: The Case of Denmark". Les ateliers de l'étique / The Ethics Forum, Vol. 6, Nr. 2, 2011, pp. 85-106.

LECLER, J. (1955) "Histoire de la tolérance au siècle de la Réforme”. Paris: Albin Michel, 1994.

LENNON, T. "Bayle, Locke and the Metaphysics of Toleration". In: STEWART, M. A. (ed.). Studies in Seventeenth-Century European Philosophy. Oxford: Clarendon Press, 1997. (Oxford Studies in the History of Philosophy II) pp. 177-195.

LOCKE, J. (1689) "Carta sobre a Tolerância". Tradução F. Fortes, W. Ferreira Lima. Organização, introdução, revisão técnica, notas e comentários F. F. Loque. Belo Horizonte: Autêntica, 2019.

. (1689) "A letter concerning Toleration and Other Writings". Edited with an Introduction by M. Goldie. Indianapolis: Liberty Fund, 2010.

. "A Letter concerning Toleration". Trans. W. Popple London: printed for Awnsham at the Black Swan at Amen-Corner, 1689.

. "A Second Letter concerning Toleration". London: printed for Awnsham and John Churchill in Ave-Mary Lane Near Pater-Noster-Row, 1690.

. (1689) "Two Treatises of Government". Ed. P. Laslett Cambridge: Cambridge University Press, 2015.

. (1689) "Dois Tratados sobre o Governo". Trad. J. Fischer São Paulo: Martins Fontes, 2005.

. (1667) "An Essay Concerning Toleration and other writings on Law and Politics, 1667-1683”. Ed. J. R. Milton and P. Milton Oxford: Clarendon Press, 2010.

Press, 2002.

"John Locke: Political Essays". Ed. M. Goldie Cambridge: Cambridge University

. "John Locke: Ensaios Políticos". Tr. E. Ostrensky São Paulo: Martins Fontes, 2007.

. "The Correspondence of John Locke". Ed. E. S. de Beer Oxford: Clarendon Press, 1976-1989. Vol. I-VIII.

LONG, T. "The Letter for Toleration decipher'd and the Absurdity and Impiety of an Absolute Toleration demonstrated". London: printed by Freeman Collins and are to be sold by R. Baldwin in the Old-Bay, 1689.

LOQUE, F. F. “Os Fundamentos da Tolerância Religiosa em John Locke" (Tese de Doutorado) Belo Horizonte, UFMG, 2019.

MACLURE, J., TAYLOR, C. "Laïcité et liberté de conscience". Montréal: Boréal, 2010. MCCABE, D. "John Locke and the argument against strict separation". The Review of Politics, Vol. 59, Nr. 2, 1997, pp. 233-258.

MILL, J. S. (1859) "On Liberty and other writings". Cambridge: Cambridge University Press, 2017.

NICHOLSON, P. “John Locke's later Letters on Toleration”. In: HORTON, J., MENDUS, S. (ed.) John Locke: A Letter Concerning Toleration In Focus. New York: Routledge, 1991. pp. 163-187. 
ORO, A. P. "A laicidade na América Latina: uma apreciação antropológica”. In: LOREA, R. A. (org.). Em defesa das liberdades laicas. Porto Alegre: Livraria do Advogado, 2008. pp. 81-96.

PORTIER, P. "A regulação estatal da crença nos países da Europa ocidental”. Religião e Sociedade, Vol. 31, Nr. 2, 2011, pp. 11-28.

RANQUETAT JR, C. A. "Laicidade, laicismo e secularização: definindo e esclarecendo conceitos". Revista Tempo da Ciência, Vol. 15, Nr. 30, 2008.

SANTOS, A. C. "O ateísmo no pensamento político de John Locke". Kriterion, Nr. 143, 2019, pp. 257-277.

SAVONIUS, S.-J. "Locke in French: The Du Gouvernement Civil of 1691 and its readers". The Historical Journal, Vol. 47, Nr. 1, 2004, pp. 47-79.

SIGMUND, P. E. "Jeremy Waldron and the Religious Turn in Locke Scholarship". The Review of Politics, Vol. 67, Nr. 3, 2005, pp. 407-418.

SILVA, S. H. S. "Tolerância Civil e Religiosa em John Locke". São Cristóvão: Ed. UFS, 2013.

STILLINGFLEET, E. “The Mischief of Separation". London: printed for Henry Mortlock at the Phoenix in St Pauls Church-yard at the White Hart in Westminster Hall, 1680. TATE, J. W. "Liberty, Toleration and Equality: John Locke, Jonas Proast and the 'Letters concerning Toleration"”. New York: Routledge, 2016.

VERNON, R. "The Career of Toleration - John Locke, Jonas Proast and after". Montreal: McGill Queen's University Press, 1997.

ZAGORIN, P. "How the Idea of Religious Toleration came to the West". Princeton: Princeton University Press, 2003. 